\title{
Оценка территориального развития субъектов России на западном участке Северного морского пути
}

\author{
В. В. Денисов ${ }^{1}$, М. В. Светлова ${ }^{2}$ 凶 \\ ${ }^{1}$ Мурманский морской биологический институт Кольского научного иентра \\ Российской академии наук, Российская Федераџия \\ (183010, г. Мурманск, ул. Владимирская, 17) \\ ${ }^{2}$ Мурманский арктический государственный университет, Российская Федерачия \\ (183038, г. Мурманск, ул. Капитана Егорова, 15)
}

\begin{abstract}
Аннотация: Цель - оценка территориального развития субъектов Российской федерации на основе экспертного метода в регионе наиболее эксплуатируемого западного участка трассы Северного морского пути.

Мeтоды. В статье рассмотрен один из методов экспертной оценки территориального развития субъектов Российской Федерации западного участка трассы Северного морского пути на примере пяти арктических приморских регионов - Мурманской области, Архангельской области, Республики Карелия, Ненецкого и Ямало-Ненецкого автономных округов. Использованы три подсистемы общего геоэкологического арктического пространства Российской Федерации: природно-экологическая, экономико-экологическая и социально-экологическая. Оценка проводилась по альтернативной пятибалльной шкале. Критерии экспертной оценки - подсистемная соразмерность и приближенность гармоничному эколого-социально-экономическому развитию.

Результаты обобщены в табличной и графической форме. Экспертная сравнительная оценка арктических приморских субъектов западного участка трассы Северного морского пути позволила выявить регионы с разной степенью территориального развития. Она определяет подсистемную координатную соразмерность и приближенность к идеальной области гармоничного эколого-социально-экономического развития каждого из пяти регионов. Результаты экспертной оценки показали, что в сравнении пяти субъектов России траектория территориального развития Мурманской области более сбалансирована, но все пять регионов пока далеки от показателей, характеризующих гармоничное развитие.

Заключение. В спектре методологических подходов к оценке сложных социо-эколого-экономических приморских систем применение данного метода представляется наиболее приемлемым для получения практически значимых результатов.
\end{abstract}

Ключевые слова: геоэкологические координаты, геоэкологическое пространство, Северный морской путь, арктические приморские региональные территории, гармоничное территориальное развитие, гармоничное эколого-социально-экономическое развитие, экспертный метод, экспертная оценка.

Для цитирования: Денисов В.В., Светлова М. В. Оценка территориального развития субъектов России на западном участке Северного морского пути // Вестник Воронежского государственного университета. Серия: География. Геоэкология, 2021, № 1, с. 37-44. DOI: https://doi.org/10.17308/geo.2021.1/3254

\section{ВВЕДЕНИЕ}

Территориальное развитие РФ охватывает различные аспекты сложнейшей проблемы региональной географии, так как зависит от решения множества актуальных вопросов. Это, в первую очередь, гармонизация отношений между Центром и территориями, рациональное природо- пользование с безусловным приоритетом сохранения природы, модернизация управленческих институтов, как федеральных, так и региональных, и другие вопросы. Принципиальным ответом на упомянутые сложности могло бы стать моделирование геоэкологических систем, которые с различной степенью приближения могут описывать

(C) В. В. Денисов, М. В. Светлова, 2021

$\triangle$ Светлова Марина Всеволодовна, e-mail: marina-svetlova@bk.ru

(c) (i) Контент доступен под лицензией Creative Commons Attribution 4.0 License. 
те самые территории и акватории, которые выступают в роли территориальных единиц РФ. Такие попытки с разной степенью конкретности предпринимаются, но успешность их часто далека от реального ответа на вышеперечисленные вопросы. Причины такой ситуации различны, а именно: концептуальные трудности территориального представления (описания) конкретных географических регионов, недостаток необходимой информации для адекватного их наполнения в процессе реализации моделей, упрощение проблемных задач. Поэтому можно заключить, что путь моделирования территориальных образований хотя и, безусловно, перспективен, но в настоящее время мало реален для получения практически значимых результатов. В процессе реализации следует опираться на другие, более простые методы. Одним из них представляется использование так называемых геоэкологических координат, предложенных в 2014 году для качественного описания исходных социально-экономических систем. Эти координаты упорядочивают многомерное понятие устойчивости развития геосистемы в трехмерном измерении. Именно её трехмерность позволяет адекватно охарактеризовать каждую из исходных подсистем - природу, экономику и общество. Точность и всеохватность такой характеристики зависят от количества выбранных показателей и доступности статистической информации.

Впервые реализация качественного подхода как элемента комплексной оценки географического положения приморских территорий появилась в нашей статье [7]. Позже этот подход был использован для оценок различных арктических приморских территорий Европейской части России $[2,3]$.

В данной статье сделана попытка объединить пять арктических регионов воедино, чтобы оценить состояние и их перспективы как действующих субъектов РФ, в пределах которых функционирует национальная транспортная магистраль - Северный морской путь (СМП).

Геоэкологические координаты как инструменты экспертной оценки территориального развития акватерриториальных береговых систем наряду с множественной концептуальной моделью предметной области морехозяйственной деятельности [1] могут выступать в качестве комплексного инструментария для решения задач экологически ориентированного управления прибрежными зонами Арктики.

\section{МЕТОДЫ ИССЛЕДОВАНИЯ}

Морское пространство СМП может быть описано, например, в рамках концепции Больших морских экосистем (БМЭ), где Баренцево море (вместе с Белым) и Карское море представлены как геоэкологическое пространство с акцентом на морскую компоненту [6]. Там же подчеркнуто, что СМП это не только собственно морские сегменты БМЭ, но и экономика и экология его обширной сухопутной части. Все три составные части качественного описания в рамках геоэкологических координат рассматриваемых пяти регионов разбиты на три подсистемы: природы, экономики и общества. Во всех трех группах были определены и выбраны по 10 геоэкологических координат (показателей).

Для удобства обработки сырых данных применялся метод балльной оценки. Баллы определялись по принятой 5-ти балльной шкале в каждой геоэкологической координате на основе экспертных оценок авторов. Благоприятным для гармоничного развития региона показателям баллы присваивались в прямом порядке, а неблагоприятным показателям (например, доля нарушенных земель, уровень заболеваемости) - в обратном порядке. Одинаковым значениям сырых данных присваивалось одинаковое количество баллов. Затем полученные баллы были суммированы.

Результаты суммирования баллов для исследуемых регионов представлены в таблице.

Во многих случаях эти баллы определялись достаточно уверенно по цифровым количественным характеристикам (статистическим данным), за исключением климатических факторов, по которым баллы устанавливались по средним многолетним характеристикам.

Для определения местоположения субъектов применялся метод физико-математического определения точек (центров тяжести) с координатами средней географической широты и долготы. Для принятых в рассмотрение пяти приморских арктических регионов более южное и более западное географическое местоположение было оценено как наиболее благоприятное, хотя переход от морского к континентальному климату потребовал экспертного заключения, основанного на общеклиматических соображениях.

Местоположение Мурманской области, Республики Карелия, Архангельской области, Ненецкого и Ямало-Ненецкого автономных округов наглядно представлены на карте (центр тяжести обозначен черной точкой) (рис. 1). 
Результаты суммирования баллов по геоэкологическим координатам Мурманской области (МО), Республики Карелия (РК), Архангельской области (АО), Ненецкого (НАО) и Ямало-Ненецкого автономных округов (ЯНАО) на 2016-2017 годы

[Table. The results of summing up points for the geoecological coordinates of the Murmansk region (MR), the Republic of Karelia (RK), the Arkhangelsk region (AR), the Nenets (NAR) and Yamal-Nenets autonomous regions (YNAR) for 2016-2017]

\begin{tabular}{|c|c|c|c|c|c|}
\hline \multirow{2}{*}{$\begin{array}{c}\text { Геоэкологическая координата / } \\
\text { Geoecological coordinate }\end{array}$} & \multicolumn{5}{|c|}{$\begin{array}{c}\text { Суммы баллов по подсистемам для регионов / } \\
\text { Subsystems cores for regions }\end{array}$} \\
\hline & $\begin{array}{l}\mathrm{MO} / \\
\mathrm{MR}\end{array}$ & $\begin{array}{c}\mathrm{PK} / \\
\mathrm{RK}\end{array}$ & $\begin{array}{l}\mathrm{AO} / \\
\mathrm{AR}\end{array}$ & $\begin{array}{l}\mathrm{HAO} / \\
\mathrm{NAR}\end{array}$ & $\begin{array}{l}\text { ЯHAO / } \\
\text { YNAR }\end{array}$ \\
\hline $\begin{array}{c}\text { Координата X } \\
\text { (суммарное количество баллов по подсистеме природы) / } \\
\text { X coordinate } \\
\text { (the total number of points for the nature subsystem) }\end{array}$ & 34 & 37 & 41 & 21 & 22 \\
\hline $\begin{array}{c}\text { Координата Y } \\
\text { (суммарное количество баллов по подсистеме экономики) / } \\
\text { Y coordinate } \\
\text { (total number of points for the economy subsystem) }\end{array}$ & 32 & 22 & 35 & 29 & 32 \\
\hline $\begin{array}{c}\text { Координата Z } \\
\text { (суммарное количество баллов по подсистеме общества) / } \\
\text { Z coordinate } \\
\text { (the total number of points for the society subsystem) }\end{array}$ & 36 & 25 & 30 & 23 & 42 \\
\hline $\begin{array}{c}\text { Общее количество баллов / } \\
\text { Total points }\end{array}$ & 102 & 84 & 106 & 73 & 96 \\
\hline
\end{tabular}

При наличии объективных статистических данных, используемых для количественного и балльного выражения показателей, и с учетом того, что число координат в каждой группе было достаточно большим (10), субъективность оценок в каждой подсистеме, так или иначе, давала достаточно надежное и близкое к реальности представление при ранжировании показателей для всех 5 регионов.

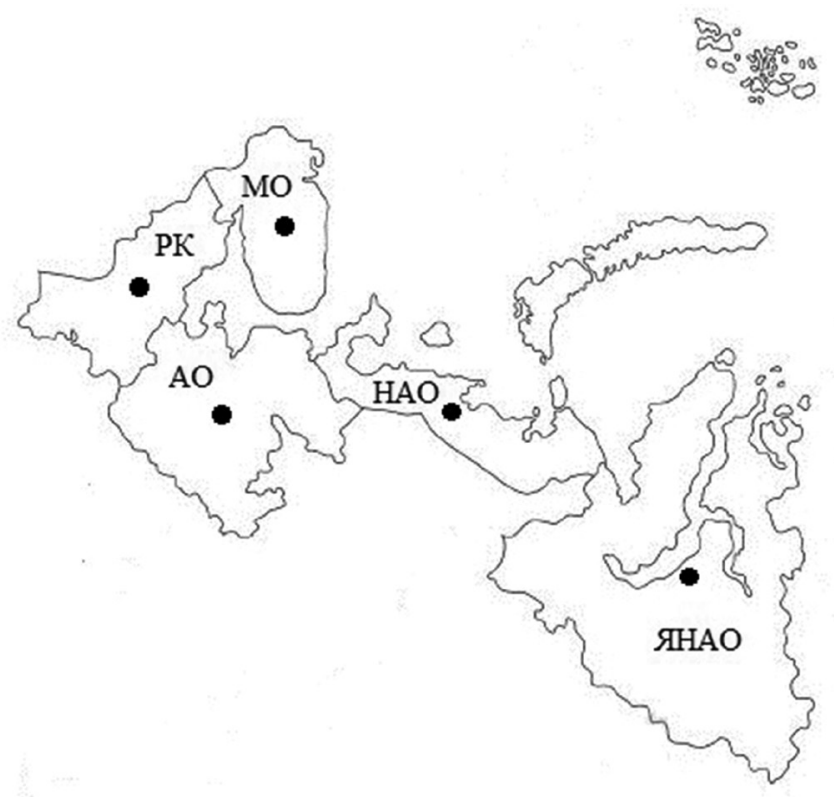

Puc. 1. Местоположение (центр тяжести) Мурманской области, Архангельской области, Республики Карелия, Ненецкого автономного округа и Ямало-Ненецкого автономного округа

[Fig. 1. Location (center of gravity) of the Murmansk region, the Arkhangelsk region, the Republic of Karelia, the Nenets Autonomous region and the Yamalo-Nenets Autonomous region] 
Общая методологическая основа примененного качественного экспертного метода более подробно изложена в [3].

Экспертная оценка гармоничности развития пяти арктических приморских субъектов РФ проводилась по двум критериям: степени подсистемной соразмерности значений геоэкологических координат и приближенности к гармоничному развитию. Первый оценивался как отклонение суммарного количества баллов по каждой из подсистем от среднего арифметического значения как мере центральной тенденции, последний - путем сопоставления достигнутого уровня развития с максимально возможным. По принятой нами методике по каждой из подсистем возможное количество баллов варьирует от минимума до максимума в интервале от $10(10 \times 1=$
10) до $50(10 \times 5=50)$, а суммарное по подсистемам - от $30(10 \times 3=30)$ до $150(50 \times 3=150)$. Максимумы соответствуют идеальной области гармоничного развития с равными значениями координат $\mathrm{X}=50$, $\mathrm{Y}=50, \mathrm{Z}=50$. В иллюстрируемом случае интервал территориального развития находится в балльных пределах от 30 до 150, что дает возможность расчета пройденного регионом пути к цели, при принятии данного интервала за $100 \%$.

\section{ОБСУЖДЕНИЕ РЕЗУЛЬТАТОВ}

Наглядно уровень гармоничности территориального развития, зафиксированный при помощи геоэкологических координат, пяти арктических приморских субъектов на 2016-2017 годы представлен на рисунке 2.

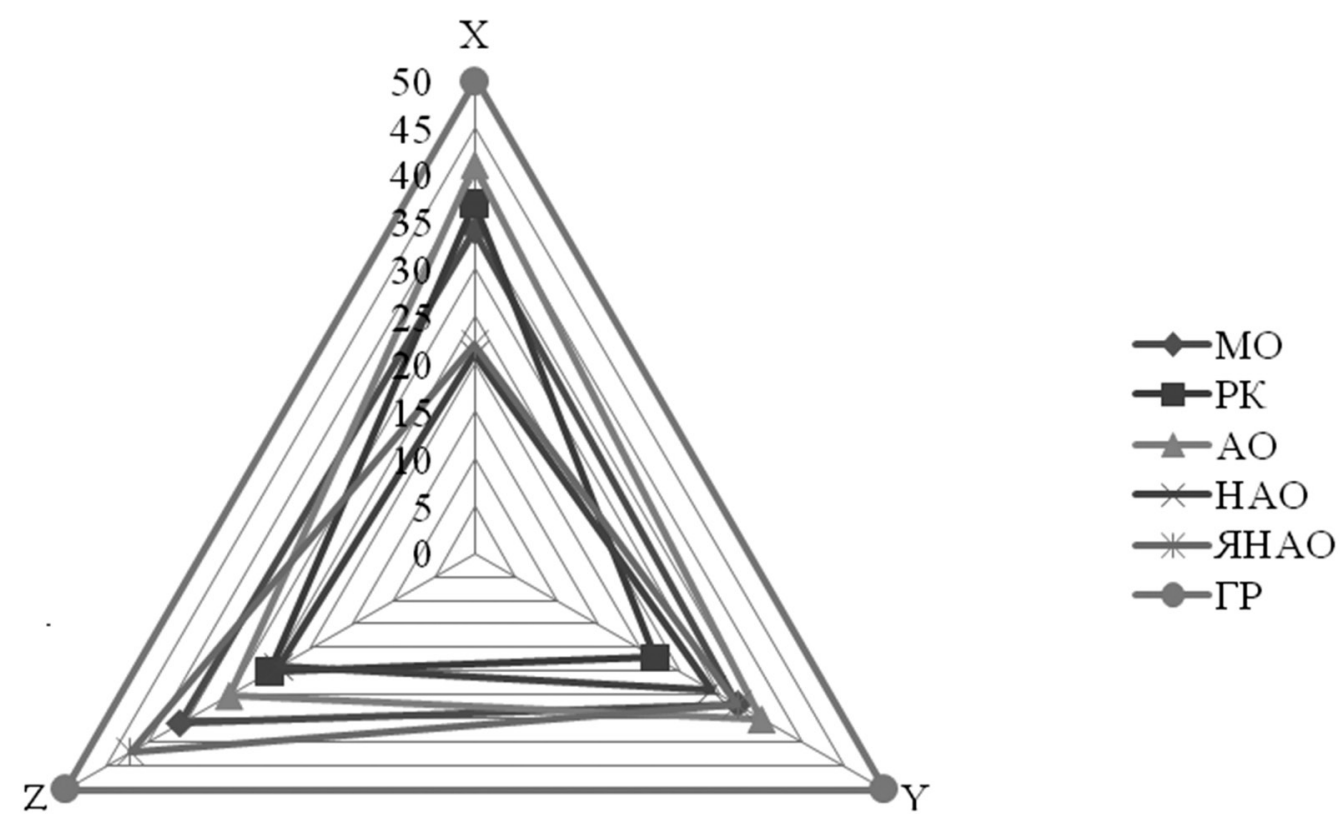

Рuc. 2. Графическое представление гармоничности территориального развития Мурманской области, Республики Карелия, Архангельской области, Ненецкого и Ямало-Ненецкого автономных округов на 2016-2017 годы

[Fig. 2. Graphic representation of the harmony of the territorial development of the Murmansk region, the Republic of Karelia, the Arkhangelsk region, the Nenets and Yamalo-Nenets autonomous regions for 2016-2017]

На рисунке 2 отражены суммарные значения баллов по подсистемам для пяти исследуемых административных единиц России, а также представлена идеальная область гармоничного развития (ГР) арктической приморской социо-эколого-экономической системы.

Следует отметить, что при относительном сходстве климатических условий Севера, отсутствие ледового периода в районе Мурманского порта является благоприятным и способствует хозяйственному освоению акватерриториального пространства и гармоничному развитию региона.

В экономике Мурманской области традиционно более высока доля морского сектора. Для морской деятельности характерна высокая степень диверсификации, что выступает важным фактором гармоничного развития приморских субъектов. Ключевыми отраслями Мурманской области считаются рыбопромысловая и транспортная отрасли. 
Рыбодобывающими компаниями Мурманска в больших объемах добываются треска и пикша. В меньших объемах ведется промысел палтуса, зубатки, камбалы, сельди и мойвы, а также семги, горбуши, кумжи, гольца. Увеличиваются объемы промысла других морепродуктов - ламинарии, креветок, кальмаров, моллюсков, морских ежей, экспортируемых преимущественно в Японию, что благоприятствует экономическому развитию Мурманской области. Перспективным направлением становится разведение и выращивание атлантического лосося, водорослей, моллюсков, морских ежей и других гидробионтов в прибрежной зоне омывающих морей. В 2017 году доля отрасли «Рыболовство и рыбоводство» в валовом региональном продукте Мурманской области составила 10,2 \% (для сравнения, в Архангельской области $-2 \%$, в Карелии - 1 \%, В НАО и ЯНАО - менее $1 \%$ ).

Один из ключевых показателей уровня развития морской транспортной отрасли - объем грузооборота крупнейшего порта.

Крупнейший морской порт в западной Арктике - Мурманский, является единственным в Европейской части РФ незамерзающим глубоководным портом (с неограниченной максимальной осадкой принимаемого судна), обеспечивающим прямой выход в Мировой океан [5]. Порт Кандалакшский (с максимальной осадкой судна 9,8 м) специализируется на перевалке сыпучих грузов, а через порт Витино (с максимальной осадкой судна 13 м) происходит перевалка нефтепродуктов.

По сравнению с Мурманским портом Архангельский морской торговый порт не такой мощный и глубоководный (максимальная осадка судна - 9,2 м). В ледовый период поддержание судоходства в Архангельском порту возможно только с помощью ледокольной проводки. Карельский Беломорский порт намного уступает по грузообороту, да к тому же замерзает в холодный период.

Крупнейший морской порт Ненецкого автономного округа - Нарьян-Мар - замерзающий (максимальная осадка принимаемого морского судна - 3,6 м), используется как одна из основных перевалочных баз для нефтяных грузов. Два других морских порта НАО - Амдерма (максимальная осадка судна -2 м) и Варандей (максимальная осадка судна - 14 м). Первый специализируется на перевалке угля, минерально-строительных, рефрижераторных грузов и горюче-смазочных материалов в бочках, второй ориентирован на экспорт нефти и нефтепродуктов и не имеет свя- зи с железнодорожной сетью России. Оба порта замерзающие. Крупнейший морской порт Ямало-Ненецкого автономного округа - Сабетта (с максимальной осадкой судна 12 м), строительство которого началось в 2012 году, также замерзающий, специализируется на перевалке сжиженного природного газ и газового конденсата.

В 2017 году грузооборот Мурманского морского порта составил 51,7 млн. т, что равно $70 \%$ от общего грузооборота портов Арктического бассейна РФ. Для сравнения, в 2017 году грузооборот порта Нарьян-Мар был равен 0,2 млн. т, Беломорского порта - 1,0 млн. т, Архангельского морского порта - около 4,0 млн. т, порта Варандей 8,2 млн. т, порта Сабетта - 8,0 млн. т. По сравнению с 2016 годом грузооборот ММП увеличился на 18,3 млн. т, порта Нарьян-Мар - на 0,1 млн. т, порта Варандей - на 0,2 млн. т, порта Сабетта почти в 3 раза - на 5,2 млн. т. Порт Сабетта в 2018 году продолжил наращивать экспортные поставки сжиженного природного газа с завода «ЯмалСПГ». Причина увеличения грузооборота в Мурманском морском порту связана с успешным возобновлением промысла мойвы в Баренцевом море, использованием новой погрузочной техники, запуском нового перевалочного комплекса «Норд» для перевалки нефти и нефтепродуктов, ростом перевалки минеральных грузов через новый балкерный терминал. Основная причина повышения грузооборота порта Варандей связана с ростом перевалки нефтепродуктов и сжиженного природного газа. Причины снижения грузооборота порта Нарьян-Мар - обмеление Печоры (по фарватеру и в районе морского порта глубина реки достигла 3,4-3,6 метров), в результате в порт не могут заходить крупнотоннажные суда.

Доля отчислений на охрану окружающей среды в Мурманской области выше в сравнении с Республикой Карелия, Архангельской областью, НАО и ЯНАО. Однако данных объемов пока недостаточно для решения геоэкологических проблем области. Данный вопрос остается актуальным на повестке дня региональных органов управления.

По социально-экологической составляющей в сравнении пяти регионов лидирует ЯНАО. Мурманская область незначительно отстает от округа.

В рейтинге регионов РФ по качеству жизни Мурманская область занимает срединное 46 место. В расчет рейтинга включены показатели экологических условий и безопасности проживания населения, здоровья и уровня образования, уровня экономического развития региона и ряд дру- 
гих. Но Мурманская область занимает достаточно высокие позиции по показателю «доля населения с высшим образованием» (21 место) и лидирует по показателю обеспеченности, отвечающей требованиям безопасности питьевой водой.

Результаты оценки гармоничности территориального развития по степени подсистемной координатной соразмерности в сравнении пяти арктических приморских субъектов показали, что значения геоэкологических координат по подсистемам у Мурманской области различаются незначительно $(\mathrm{X}=34, \mathrm{Y}=32, \mathrm{Z}=36)$, при среднем арифметическом 34 балла и максимальном отклонении от него 2 балла $(36-34=2)$. В то время как у других исследуемых арктических приморских регионов различия более значительные. Так, у Республики Карелия среднее арифметическое в баллах составляет 28, максимальное отклонение от него - 9; у Архангельской области - 35,3 и 5,6; у НАО - 24,3 и 4,7; у ЯНАО - 32 и 10, соответственно.

Суммарное значение геоэкологических координат у Мурманской области несколько ниже, чем у Архангельской, и намного выше, чем у НАО и Республики Карелия. Так, сумма значений геоэкологических координат для Мурманской области составляет 102 балла, для Архангельской области 106 баллов, для Республики Карелия - 84, для НАО - 73, для ЯНАО - 96 баллов. При этом степень приближенности к идеальной области гармоничного развития Мурманской области составляет 56,6 \%, Архангельской области - 58,8 \%, Республики Карелия $-46,6 \%$, НАО - 40,5 \%, ЯНАО - 53,3\%.

\section{ЗАКЛЮЧЕНИЕ}

В сравнении пяти регионов траектория развития Мурманской области более сбалансирована, но все пять регионов пока далеки от показателей, характеризующих гармоничное эколого-социально-экономическое развитие.

Несмотря на разные у каждого региона аспекты гармоничного развития, главной общей чертой выступает возможность транспортной мобильности как связующего звена по перемещению продуктов производства морским и железнодорожным транспортом в другие части мирового и регионального рынка. Поэтому большую сбалансированность на гармоничное развитие Мурманской области можно объяснить тем, что ее расположение в крайней западной точке Северного морского пути исторически предопределило тот вывод, что на данном этапе проводимого исследования она оказалась выше других рассматриваемых в статье субъектов РФ по общему уровню цивилизованности и благоприобретения, чему в немалой степени способствовала военная составляющая области стратегически важного форпоста, гаранта защиты всего российского арктического пространства.

\section{СПИСОК ЛИТЕРАТУРЫ}

1. Вицентий А. В., Гогоберидзе Г.Г., Шишаев М. Г., Ершова А.А., Ломов П.А., Румянцева Е.А. Концептуальная модель предметной области морехозяйственной деятельности Мурманской области как инструмент согласования деятельности морепользователей // Maтериаль ХХVII Международной береговой конференции «Арктические берега: путь к устойчивости». Мурманск, 2018, с. 320 - 323.

2. Денисов В.В., Светлова М.В. Геоэкологические координаты как инструмент экспертной оценки устойчивости эколого-экономических систем при решении задач управления морским природопользованием // Вестник Кольского научного ичентра РАН, 2016, № 4 (27), с. 73 - 85 .

3. Денисов В. В., Светлова М. В. Комплексная оценка эколого-географического положения приморских территорий (на примере Мурманской области). Мурманск: МАГУ, 2017. 145 с.

4. Денисов В. В., Светлова М. В. Применение качественных методов в оценке акватерриториальных береговых систем Арктики // Материаль XXVII Международной береговой конференции «Арктические берега: путь к устойчивости». Мурманск, 2018, с. 269 - 272.

5. Жигунова Г. В., Меньшакова М. Ю., Светлова М. В., Хубер М., Яковлева О.А. Модернизация высокоширотных приморских городских систем в контексте устойчивого развития (на примере города Мурманска) // Becmник Воронежского государственного университета. Серия: География. Геоэкология, 2018, № 3, с. 36 - 43.

6. Матишов Г.Г., Денисов В.В., Дженюк С.Л., Жичкин А.П. Морское пространство трансатлантической зоны Севморпути в рамках концепции больших морских экосистем // Вестник Кольского научного ичентра РАН, 2016, № 4 (27), с. 86 - 98.

7. Светлова М. В. Эколого-географическое положение Мурманской области: основные аспекты // Научные ведомости Белгородского государственного университета. Серия: Естественные науки, 2011, № 21 (116), вып. 17, с. 183 - 190.

Конфликт интересов: Авторы декларируют отсутствие явных и потенциальных конфликтов интересов, связанных с публикацией настоящей статьи.

Поступила в редакцию 05.09.2018 Принята к публикащии 02.03.2021 


\title{
Assessment of the Territorial Development of Russia's Regions on the Western Part of the Northern Sea Route
}

\author{
V.V. Denisov ${ }^{1}$, M.V. Svetlova ${ }^{2}$ 府 \\ ${ }^{1}$ Murmansk Marine Biological Institute, Kola Scientific Centre, Russian Academy of Sciences, \\ Russian Federation \\ (17, Vladimirskaya St., Murmansk, 183010) \\ ${ }^{2}$ Murmansk Arctic State University, Russian Federation \\ (15, Captain Yegorov St., Murmansk, 183038)
}

\begin{abstract}
The purpose is to assess the territorial development of the Russian Federation subjects based on the expert method in the region of the most exploited Western section of the Northern Sea Route.

Methods. The article considers one of the methods of expert assessment of territorial development of the subjects of the Russian Federation of the Western section of the Northern sea route on the example of five Arctic coastal regions - Murmansk region, Arkhangelsk region, Republic of Karelia, Nenets and Yamal-Nenets Autonomous regions. Three subsystems of the General geoecological Arctic space of the Russian Federation are used: natural-ecological, economic-ecological and social-ecological. The assessment was carried out on an alternative five-point scale. Expert assessment criteria - subsystem proportionality and closeness to harmonious ecological-socio-economic development.

Results. The results are summarized in tabular and graphical form. An expert comparative assessment of the Arctic coastal regions of the Western section of the Northern sea route revealed regions with different degrees of territorial development. It determines the subsystem coordinate proportionality and proximity to the ideal area of harmonious ecological-socio-economic development of each of the five regions. The results of the expert assessment showed that in comparison with the five subjects of Russia, the trajectory of territorial development of the Murmansk region is more balanced, but all five regions are still far from indicators that characterize harmonious development.

Conclusions: In the range of methodological approaches to the assessment of complex socio-ecological and economic coastal systems, the application of this method seems to be the most appropriate for obtaining practically significant results.
\end{abstract}

Key words: geoecological coordinates, geoecological space, the Northern Sea Route, Arctic coastal regional territories, a harmonious territorial development, harmonious environmental and socio-economic development, expert method, expert evaluation.

For citation: Denisov V. V., Svetlova M. V. Assessment of the Territorial Development of Russia's Regions on the Western Part of the Northern Sea Route. Vestnik Voronezskogo gosudarstvennogo universiteta. Seria: Geografia. Geoekologia, 2021, no. 1, pp. 37-44. (In Russ.) DOI: https://doi.org/10.17308/geo.2021.1/3254

\section{REFERENCES}

1. Vitsentiy A. V., Gogoberidze G. G., Shishayev M. G., Yershova A.A., Lomov P.A., Rumyantseva E.A. Kontseptual'naya model' predmetnoy oblasti morekhozyaystvennoy deyatel'nosti Murmanskoy oblasti kak instrument soglasovaniya deyatel'nosti morepol'zovateley [Conceptual model of the subject area of marine economic activity of the Murmansk region as a tool for coordinating the activities of sea users]. Materialy XXVII Mezhdunarodnoy beregovoy konferentsii «Arkticheskiye berega: put' k ustoychivosti». Murmansk, 2018, pp. 320 - 323. (In Russ.)

2. Denisov V.V., Svetlova M.V. Geoekologicheskiye koordinaty kak instrument ekspertnoy otsenki ustoychivosti ekologo-ekonomicheskikh sistem pri reshenii zadach upravleniya morskim prirodopol'zovaniyem [Geoecological coordinates as a tool for expert assessment of the sus-

(C) Denisov V. V., Svetlova M.V., 2021

$\triangle$ Marina V. Svetlova, e-mail: marina-svetlova@bk.ru 
tainability of ecological and economic systems in solving problems of marine nature management]. Vestnik Kol'skogo nauchnogo tsentra RAN, 2016, no 4 (27), pp. 73 - 85. (In Russ.)

3. Denisov V.V., Svetlova M. V. Kompleksnaya otsenka ekologo-geograficheskogo polozheniya primorskikh territoriy (na primere Murmanskoy oblasti) [Comprehensive assessment of the ecological and geographical position of coastal territories (on the example of the Murmansk region)]. Murmansk: MAGU, 2017. 145 p. (In Russ.)

4. Denisov V. V., Svetlova M. V. Primeneniye kachestvennykh metodov v otsenke akvaterritorial'nykh beregovykh sistem Arktiki [Application of qualitative methods in the assessment of the Arctic coastal systems]. Materialy XXVII Mezhdunarodnoy beregovoy konferentsii «Arkticheskiye berega: put' $k$ ustoychivosti». Murmansk, 2018, pp. 269 - 272. (In Russ.)

5.Zhigunova G. V., Menshakova M. Yu., Svetlova M. V., Khuber M., Yakovleva O. A. Modernizatsiya vysokoshirotnykh primorskikh gorodskikh sistem v kontekste ustoychivogo razvitiya (na primere goroda Murmanska) [Modernization of high-latitude coastal urban systems in the context of sustainable development (on the example of the

\section{Денисов Владимир Васильевич}

доктор географических наук, профессор, главный научный сотрудник лаборатории океанографии и радиоэкологии Мурманского морского биологического института Кольского научного центра РАН, г. Мурманск, Российская Федерация, ORCID: 0000-0001-8355-5172, e-mail: denisov@mmbi.info

Светлова Марина Всеволодовна

кандидат географических наук, доцент кафедры естественных наук Мурманского арктического государственного университета, г. Мурманск, Российская Федерация, ORCID: 0000-0002-1358-1081, e-mail: marina-svetlova@bk.ru city of Murmansk)]. Vestnik Voronezskogo gosudarstvennogo universiteta. Seria: Geografia. Geoekologia, 2018, no 3, pp. 36 - 43. (In Russ.)

6. Matishov G.G., Denisov V.V., Dzhenyuk S.L., Zhichkin A.P. Morskoye prostranstvo transatlanticheskoy zony Sevmorputi v ramkakh kontseptsii bol'shikh morskikh ekosistem [The sea space of the transatlantic zone of the Northern Sea Route within the framework of the concept of large marine ecosystems]. Vestnik Kol'skogo nauchnogo tsentra RAN, 2016, no 4 (27), pp. 86 - 98. (In Russ.)

7. Svetlova M. V. Ekologo-geograficheskoye polozheniye Murmanskoy oblasti: osnovnyye aspekty [Ecological and geographical position of the Murmansk region: main aspects]. Nauchnyye vedomosti Belgorodskogo gosudarstvennogo universiteta. Seria: Yestestvennyye nauki, 2011, no 21 (116), v. 17, pp. 183 - 190. (In Russ.)

Conflict of interests: The authors declare no information of obvious and potential conflicts of interest related to the publication of this article.

Received 05.09.2018

Accepted 02.03.2021

\section{Vladimir V. Denisov}

Dr. Sci. (Geogr.), Professor, Chief Scientific Researcher of the Laboratory of Oceanography and Radioecology of the Murmansk Marine Biological Institute of the Kola Scientific Centre of the Russian Academy of Sciences, Murmansk, Russian Federation, ORCID: 0000-00018355-5172, e-mail: denisov@mmbi.info

Marina V. Svetlova

Cand. Sci. (Geogr.), Associate Professor of the Department of Natural Sciences of the Murmansk Arctic State University, Murmansk, Russian Federation, ORCID: 0000-0002-1358-1081, e-mail: marina-svetlova@bk.ru 